\title{
THE DEVELOPMENT OF AN ONLINE INTERACTIVE RESOURCE FOR ENHANCING MOTIVATION IN SWIMMERS
}

\author{
A Master's Project \\ presented to \\ the Faculty of California Polytechnic State University, \\ San Luis Obispo
}

\begin{abstract}
In Partial Fulfillment
of the Requirements for the Degree

Master of Science in Kinesiology
\end{abstract}

by

Richard Judson Clark

June 2011 
(C) 2011

Richard Judson Clark

ALL RIGHTS RESERVED 


\section{COMMITTEE MEMBERSHIP}

TITLE:

The Development of an Online Interactive Resource for

Enhancing Motivation in Swimmers
AUTHOR:
Richard Judson Clark
DATE SUBMITTED: June 2011
COMMITTEE CHAIR: Camille P. O’Bryant, Ph.D.

COMMITTEE MEMBER: Kellie Green Hall, Ph.D.

COMMITTEE MEMBER: Suzanne Phelan, Ph.D. 


\begin{abstract}
The Development of an Online Interactive Resource for Enhancing Motivation in Swimmers
\end{abstract}

Richard Judson Clark

Research pertaining to motivation in athletics and the link that it has to continued participation in sport is widespread. Despite the resources available, adolescents continue to drop out of sports at alarming rates. The purpose of this project was to create an online tool and resource center to enhance motivation in swimmers that participate in a year-round swim program in San Luis Obispo, California. The development of the site http://athletenet.net was created based on research linked to the Self-Determination, Cognitive Evaluation, Reversal, and Achievement Goal Theories.

Swimmers can login to the website to set a variety of goals including practice/technique goals, short-term goals, long-term goals, and dream goals. More importantly, swimmers have the option to share these goals with their coaches via the website. Additional features for swimmers include daily practice ratings, daily journals, team blog, and performance charts for practice and meet results.

The tools that have been created for the swimmers on the website are based on research that supports an athlete-directed environment in which coaches empower their athletes to define their own success. Future research could include empirical studies in which researchers examine the extent to which these interactive tools enhance intrinsic motivation and decrease dropouts among swimmers.

Keywords: athletics, athletes, swimming, coaching, motivation, goal, self-determination, cognitive evaluation, reversal theory, achievement goal theory, interactive tools 


\section{ACKNOWLEDGEMENTS}

First and foremost I must thank my wife, Nara and my kids, Amberly, Toby, and Kelton for their patience and support in my quest for earning my Master's degree. To my Mom, although you are not here to share this achievement with me, it is the passion for learning and knowledge that you and Dad instilled in me that was the driving force behind my goal to complete my Master's Project.

The greatest lessons I have learned have been about perseverance, and Dr. Camille O'Bryant has provided me the confidence to forge ahead even in the most challenging of times. Thank you so much Dr. O'Bryant for your guidance and motivation to help me finish my motivation project. To Dr. Kellie Green Hall, and Dr. Suzanne Phelan, your time, feedback and support were much appreciated. 


\section{TABLE OF CONTENTS}

Page

LIST OF TABLES .........................................................................................

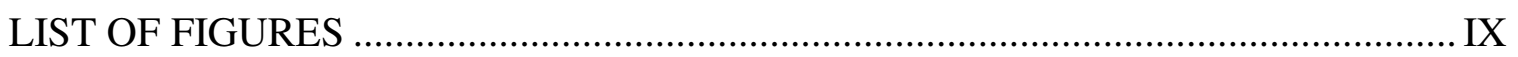

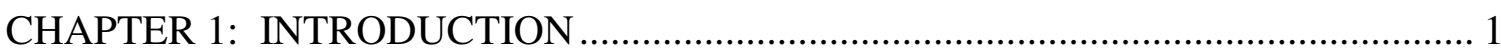

Background of the Project ............................................................ 1

Statement of the Problem and Purpose .................................................. 3

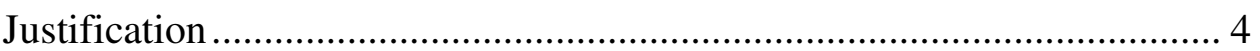

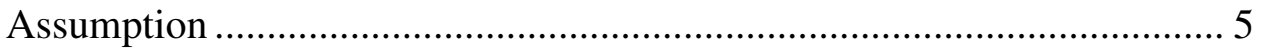

Definitions of Terms .............................................................................. 5

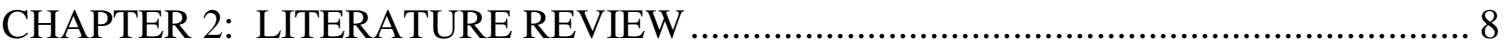

Theoretical Foundation(s) of Motivation.............................................. 8

Donkey and Stork Approach to Coaching and Motivation .............. 10

Athlete-Directed and Ego-Centered Coaching Styles ..................... 11

The Motivational Link between Athletics and Education ...................... 12

Maslow's Hierarchy of Needs ............................................................ 18

Self-Determination Theory ............................................................. 20

Achievement Goal Theory ........................................................... 23

Reversal Theory ............................................................................ 24

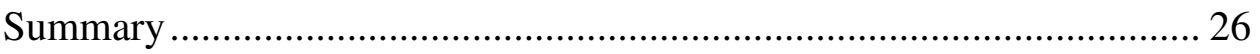

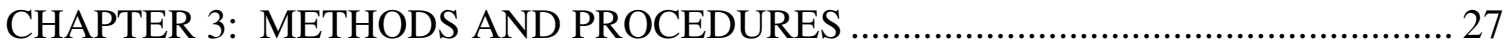

Development of the Website................................................................ 27

Ethical Considerations and Responsible Use..................................... 28

Website Components ................................................................... 28

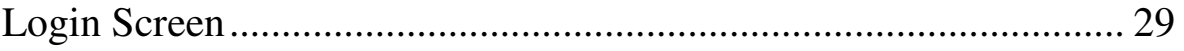

Home Page for Swimmers ........................................................... 30

Goal-Setting Page for Swimmers .................................................. 31

Journal Page for Swimmers .......................................................... 32

Practice Performance Rating Page for Swimmers .......................... 33

Performance Charts and Graphs for Swimmers ............................. 34

Competition Results for Athletes.................................................. 35

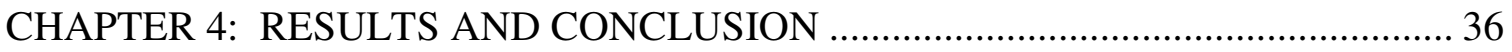

Overview of Project ................................................................. 36

Athlete Evaluation ................................................................. 36

Swimmer Feedback.................................................................. 37 
The Athlete Network: Future Possibilities and Capabilities.................... 38

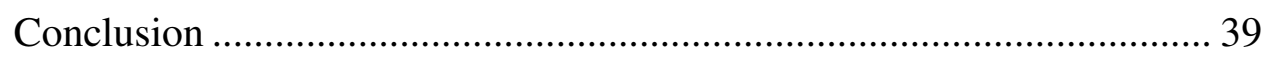

Recommendations and Suggestions for Future Studies........................ 40

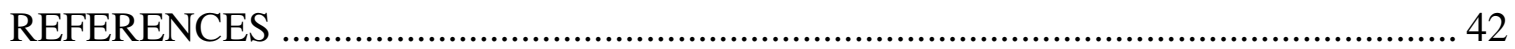




\section{LIST OF TABLES}

Page

Table 4.1: Swimmer Response to Website Tools ..............Error! Bookmark not defined. 


\section{LIST OF FIGURES}

Figure 1.1: Sports Participation vs. Sports Dropout ................................................ 3

Figure 1.2: USA Swimming 2010 Renewal Rates Compared to 2009 Annual Members. 5

Figure 2.1: Goal Setting. Motivation and Self-Efficacy Acting as a Continuum ............. 9

Figure 2.2: Paradigm Shift from Extrinsic Motivation to Intrinsic Motivation............... 12

Figure 2.3: Components that Can Enhance Intrinsic Motivation ................................ 15

Figure 2.4: Extrinsic Reward and Intrinsic Motivation .......................................... 16

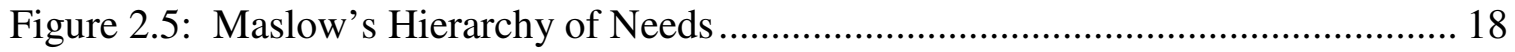

Figure 2.6: Theoretical Makeup of Motivation......................................................... 20

Figure 3.1: Athletenet.net Login Page for Puma Aquatic Team Swimmers .................. 29

Figure 3.2: Athletenet.net Home Page for Swimmers .......................................... 30

Figure 3.3: Athletenet.net Goal Setting Page for Swimmers.................................... 31

Figure 3.4: Athletenet.net Journal Page for Swimmers ............................................ 32

Figure 3.5: Athletenet.net Practice Performance Rating Page for Swimmers ................ 33

Figure 3.6: Athletenet.net Athlete Performance Chart for Swimmers............................ 34

Figure 3.7: Athletenet.net Competition Results for Athletes...................................... 35

Figure 4.1: Potential Areas of Use for the Software ............................................... 39 


\section{CHAPTER 1: INTRODUCTION}

\section{Background of the Project}

For the past 15 years I have been involved in coaching swimmers and running aquatics programming throughout San Luis Obispo County. As a coach it has been incredibly fulfilling to work with adolescents that have continued to participate in my program for a number of years and even more rewarding when swimmers have continued to swim well into adulthood. For me, success as a coach is determined not by how many Olympians come out of a program but rather by how many lives have been positively affected by participation in that program.

I have observed what I believe is a direct relationship between how motivated and engaged athletes are within the program environment and those athletes' continued participation in sports. Traditionally, I have asked competitive swimmers to keep daily journals and define their own goals beginning at the age of 12. Athletes have always been encouraged to schedule one-on-one goal setting and goal maintenance meetings with their coaches. Many swimmers show excitement and interest in keeping journals and setting goals for a few weeks after a team meeting but a very small percentage continue to write in their journals and track their goals on a daily basis.

The idea of developing an online interactive tool and resource center for athletes was born out of my frustration that athletes were not taking advantage of the resources available to them. The traditional method of goal setting and journal writing using a pad of paper and a pen is somewhat archaic to the current generation of technologically savvy athletes. An online toolbox that offers an array of motivational resources presents athletes 
with a platform in which they can relate and more importantly help define their own success.

Research supports the theory that participation in sports relies on an athlete's drive, which is also known as motivation. To better understand motivation, a basic glimpse of what comprises motivation is necessary. Anshel (2003) defined motivation as "the tendency for the direction and selectivity of behavior to be controlled by its connections to consequences, and the tendency of this behavior to persist until a goal is achieved" (p. 76). Participation in sports solely for the enjoyment of the activity is known as intrinsic motivation. Research has found that individuals with high levels of intrinsic motivation are more likely to continue participating in sports. Conversely, extrinsic motivation is based on an athlete's participation in order to receive external rewards such as trophies, ribbons, or money. Research has found that if too much emphasis is placed on extrinsic motivation, athletes are susceptible to amotivation (which occurs when an athlete has lost interest in the sport), and drop out of the sport is likely.

As shown in Figure 1.1, it has been estimated that between 20-30 million children between the ages of 6-18 years old participate in organized sports and that $80 \%$ will drop out of sports by the age of 12 (University of Indiana, 2011). Participation in recreational and competitive sports can be beneficial to adolescents both physically and psychologically (Reinboth \& Duda, 2006). Much of the blame for the lack of motivation for athletes to continue sports is that the sport is no longer considered fun (Responsible Sports, 2011). External pressure from coaches, parents, and peers to compete and perform at certain levels can also turn adolescents away from sports (Ullrich-French \& Smith, 2006). 


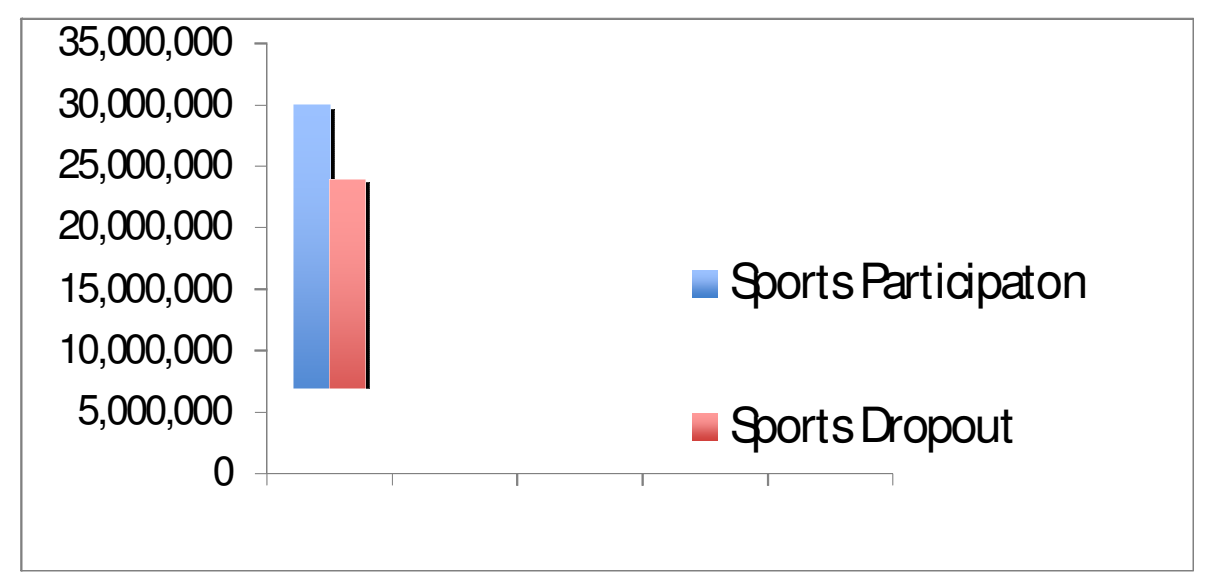

Figure 1.1: Sports Participation vs. Sports Dropout

Sports participation for 6-18 year olds. Dropout rates are by the age of 12 (from University of Indiana, 2011)

Despite the high numbers of dropouts, there is hope that athletes with a bevy of resources available to them will sustain their motivation. With the right tools to deliver information to athletes, attrition rates have a tremendous opportunity to improve. For this to happen, a paradigm shift favoring intrinsic motivation versus extrinsic motivation needs to take place. To accomplish this shift, vital steps need to take place to effectively communicate and educate athletes, parents, and coaches. The goal of this project was to provide a platform to provide athletes with the necessary tools to communicate, educate, and promote intrinsic motivation within athletics.

\section{Statement of the Problem and Purpose}

There are ample resources and research pertaining to motivation and youth athletics, and it is widely accepted that performance and participation in adolescent sports relies on motivation. However, athletes continue to drop out of sports at alarming rates. Therefore, the purpose of this project was to provide an interactive online "toolbox" or 
resource center to benefit and educate athletes. The overall objective was to use primary constructs of motivation and disseminate the information in a medium that engages a modern and technologically savvy generation.

An integral part of the online toolbox is its avenues for greater communication between coaches, athletes, and parents, which helps create and maintain an environment that cultivates intrinsic motivation. Ultimately, athletes can establish a variety of practice and competition goals, keep an online journal, rate performance and effort, and communicate with teammates and coaches on a team blog en-route to continued participation and self-efficacy.

\section{Justification}

Participation in adolescent sports can provide many benefits to athletes both physically and psychologically (Blanchard, Mask, Vallerand, de la Sablonniere, \& Provencher, 2007). If attrition rates continue to climb, fewer adolescents will continue to participate in sports and their health and well-being may be in jeopardy. The Center for Disease Control reported that from 2007-2008, 17\% of children and adolescents between the ages of 2-19 were obese (CDC, 2011). As physical activity is a prime deterrent to obesity, the lack of physical activity in many children could be a large factor in causing this epidemic.

In 2010, USA Swimming released statistical data on athlete retention rates compared to 2009 annual memberships. Only $70 \%$ of athletes registered in 2009 registered again in 2010. The 8-9 year age groups experienced the biggest drop off rates out of any other age group reported (USA Swimming, 2011). 


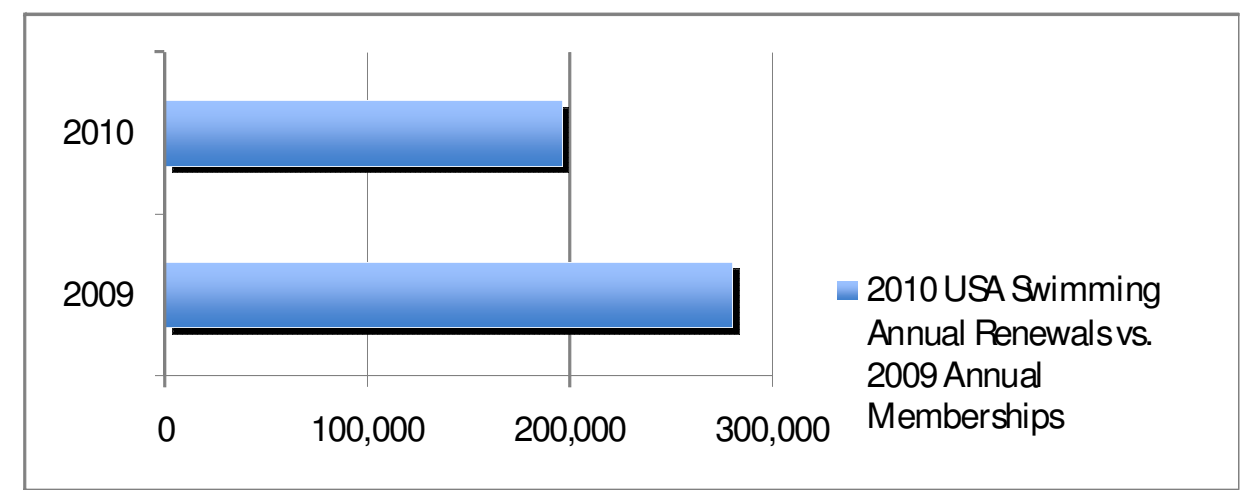

Figure 1.2: USA Swimming 2010 Renewal Rates Compared to 2009 Annual Members Data shows that only 70\% of 2009 USA Swimming members renewed again in 2010.

\section{Assumption}

The primary assumption that serves a foundation for this project is that if coaches are able to provide a safe, positive and motivating environment, then attrition rates in sports will improve and more adolescents will remain physically active.

\section{Definitions of Terms}

Amotivation. A lack of interest to continue the behavior or participation in sport. (Boiche \& Sarrazin, 2007). Amotivation is often times a precursor to burnout.

Autonomy. The ability of individuals to implement their own ideas and choices into any given situation. Athletes with higher levels of autonomy are typically ones who are higher in self-efficacy and intrinsic motivation (Sit \& Lindner, 2005).

Burnout. Long-term exhaustion and diminished interest (Kraft, 2006). Athletes may experience both physical and psychological exhaustion en-route to burnout. Once an athlete reaches burnout, further participation in that activity is unlikely. 
External Reward. Tangible goods rewarded for performance outcomes (Martens, 1987). Trophies, medals, certificates, ribbons, and money are examples of external rewards. The term 'external reward' is closely related to extrinsic motivation and in many cases the terms can be interchangeable when reviewing current research on motivation.

Extrinsic Motivation. Drive to accomplish a task fueled by external forces or rewards. Research has shown that athletes driven by extrinsic motivation are more likely to drop out of sports than athletes with high levels of intrinsic motivation (Anshel, 2003).

Intrinsic Motivation. Self-determination, inner desire, and situations in which the reward is the simple satisfaction and pure enjoyment of performing the task (Martens, 1987). Athletes that exhibit high levels of intrinsic motivation are more likely to continue participation in sports and exhibit high levels of self-efficacy.

Goal Setting. "Goals provide a sense of direction and purpose" (Goldstein, 1994, p. 96) and are positively correlated to intrinsic motivation and optimal levels of selfconfidence (Martens, 1987). A key feature of the Athlete Network is an avenue for swimmers to develop, monitor, edit, and create a variety of goals to help foster an environment that promotes intrinsic motivation.

Motivation. "The tendency for the direction and selectivity of behavior to be controlled by its connections to consequences and the tendency of this behavior to persist until a goal is achieved" (Anshel, 2003, p. 76).

Self-efficacy. People are likely to engage in activities to the extent that they perceive themselves to be competent at those activities (Bandura, 1997). Athletes who have a good self-perception and high levels of self-efficacy also exhibit high levels of 
intrinsic motivation. An athlete with self-efficacy is likely to continue participating in sports (Reinboth \& Duda, 2005). 


\section{CHAPTER 2: LITERATURE REVIEW}

It is widely accepted that performance and participation in adolescent sports rely on motivation. However, despite all of the resources and research that supports the links between motivation and sport participation, athletes continue to drop out of sports at alarming rates. Therefore, the purpose of this project was to provide an interactive online "toolbox" or resource center to benefit and help educate athletes, parents, and coaches. The overall objective was to use primary constructs of motivation and disseminate the information in a medium that engages a modern and technical savvy generation. This chapter contains a) an overview of the theoretical foundations of motivation, b) motivational links between sport and education and c) an in depth review of the SelfDetermination Theory, Achievement Goal Theory, and Reversal Theory.

\section{Theoretical Foundation(s) of Motivation}

Deci \& Ryan's $(1985,1991)$ creation of the Self-Determination Theory and Cognitive Evaluation Theory has had a broad impact on how motivation has been researched. The Self-Determination Theory is a framework designed to study how people are motivated and the effects that their personality might have on motivation. The Cognitive Evaluation theory can be considered a sub-category of the Self-Determination Theory with the notion that behavior can be intrinsically motivated, extrinsically motivated, or amotivated (Beaudoin, 2006). Intrinsic motivation is simply engaging in an activity for the pure enjoyment and satisfaction of the activity. A person with intrinsic motivation will continue an activity without the need for external rewards or incentives. 
On the other hand, extrinsic motivation focuses on tangible rewards for participation. External pressure from others and incentives for rewards for engaging in an activity are largely the makeup of extrinsic motivation. Amotivation refers to behavior that does not include either intrinsic or extrinsic motivation and results in a lack of motivation for an activity. In sport, amotivation will usually result in dropout.

Achievement and competitive orientations are also important factors to consider when defining motivation in sports. There are two primary orientations: a mastery/task orientation and an outcome orientation (Ames, 1992; Duda, 1989; Duda, Chi, Newton, Walling, \& Catley, 1995). The mastery/task orientation is based on the concept of intrinsic motivation and the theory that achievement outcomes are a reflection of selfefficacy and drive. On the other hand, outcome orientation is the focus on the overall results of a particular competition or game that is driven by external motivation.

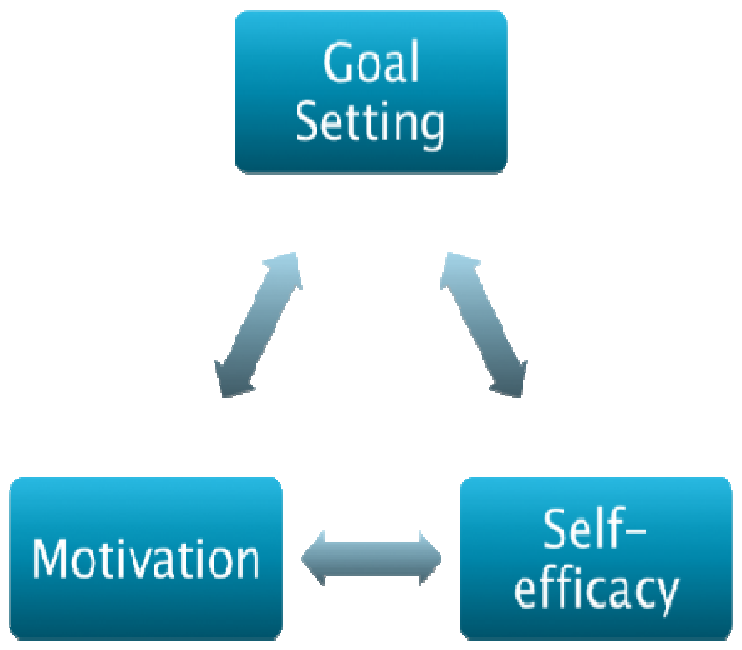

Figure 2.1: Goal Setting. Motivation and Self-Efficacy Acting as a Continuum 


\section{Donkey and Stork Approach to Coaching and Motivation}

Rainer Martens (1987) classified motivation used by many coaches into two categories: either "The Donkey Approach" or "The Stork Approach.” In the "Donkey Approach" the coach views their athletes as if they don't know anything and that the only valid source of information comes from the coach. In this system, there is usually a reward and punishment that can even lead to physical or psychological abuse. Athletes may be motivated by fear to do what the coach wants just to avoid the inevitable punishment. On the other end of the spectrum, "The Stork Approach," it is assumed that coaches are the deliverers of motivation only when they choose. In this scenario, the coach views all athletes as having one goal that will be satisfied by the coach. The athlete doesn't have a voice and it is believed that all athletes are motivated by the same techniques. Athletes are likely to be afraid to communicate with their coach about what their needs are in this approach. If communication does occur, the coach does not really listen and take into account that each individual may have different needs. "The Stork Approach" is somewhat of a "cookie cutter" approach to motivation. The workload on the coach decreases but the quality and level of motivation in the program diminishes.

Neither of these approaches are the healthiest ways to achieve motivation in athletes or students. However, they are important when discussing motivation because many people have had a teacher or coach that used either the "Donkey" or "Stork" approaches. Knowing what "not to do" can aid in the development of a quality motivational model that can be effective in both the athletic and educational settings. 


\section{Athlete-Directed and Ego-Centered Coaching Styles}

Baric \& Bucik (2009) conducted an original scientific paper on the motivational differences in athletes trained by coaches of different motivational and leadership profiles. One of the profiles used for the coaches is similar to Marten's "Donkey" and "Stork" approach to coaching. The two categories of coaching methods reviewed were "less athlete-directed, high ego-centered" coaches (Donkey and Stork approach) and "athlete-directed, low ego-oriented" coaches.

Coaches submitted self-evaluations of their coaching styles and the researchers placed them into one of two coaching categories. All athletes were a part of a team sport and asked to provide evaluations of their coaches' leadership styles. Based on the athlete questionnaires and coaches surveys a motivational marker was created for both categories of leadership styles.

The athletes that were a part of a team that had athlete-directed, low ego-oriented coaches showed higher levels of intrinsic motivation and self-worth than the athletes that were a part of the less athlete-directed, high ego-oriented coaching leadership style. In fact, the athletes that had the less athlete-directed, high ego-oriented coaches "perceived fewer signs of the mastery motivational climate in their teams, were less intrinsically motivated, and their task orientation and ego goal orientation were lower" (Baric \& Bucik, 2009, p.181).

The results of Baric and Bucik's scientific paper reiterated the importance of coaches developing an environment in which the athletes have a voice and ownership of their participation in sport. To develop an effective motivational environment, it is important for coaches to first understand the needs of their athletes. By offering a safe, 
challenging, and fun environment, athletes have the opportunity to be engaged in a purposeful activity that can increase self-efficacy (Sit \& Lindner, 2005).

The ultimate goal is for athletes to feel worthy and successful. This leads to a positive self-image and an athlete that is more likely to continue participation due to the simple enjoyment of the activity. The two most important needs for coaches to offer their athletes are to have fun, and to feel worthy (Martens, 1987).

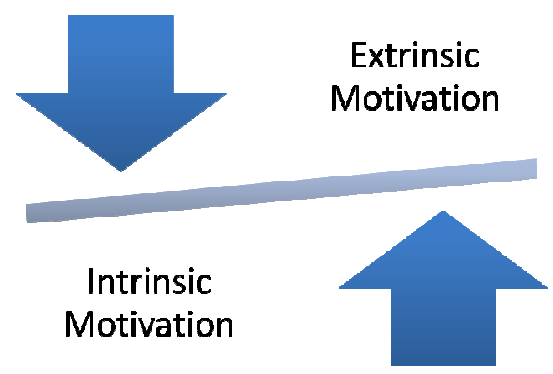

Figure 2.2: Paradigm Shift from Extrinsic Motivation to Intrinsic Motivation Research supports the need for intrinsic motivation to take precedence over extrinsic motivational strategies to encourage continued participation in sport.

\section{The Motivational Link between Athletics and Education}

Research that supports the need for athletes to have fun and feel worthy is also valid in academics. If something isn't interesting in school, or the teacher doesn't present the material in a way that invokes excitement and engagement, boredom will occur. It is the teacher's responsibility to develop lessons that can relate to the students' lives and interests by creating a safe environment and making learning fun. The University of Oregon's (2002) online educational resource offers some great information for teachers to use in the classroom to aid in keeping students motivated. All of this information is effective for coaches as well since they are in many cases the most influential "teacher" 
an athlete will ever have. Below is an overview of the valuable information offered on the website.

- Encourage students to be active in class.

- Prepare coursework in a way that you are excited about.

- Relate coursework to the lives of students to make it meaningful.

- Frequently ask questions in a way to keep class active and hands-on.

- Mix in visual aids, group interaction, and self-discovery learning methods.

- Create work that students take pride and accountability for.

- Be clear in the syllabus what is expected of your students and give clear guidelines for class work/project.

- Provide office hours and additional avenues for students to effectively communicate.

- Make the effort to check in with students in non-threatening ways that are a little apprehensive in your class.

Through effective planning, being excited about teaching, and offering a safe and open environment, teachers can empower students to excel and learn (University of Oregon, 2002.)

In 2011, Thoonen, Sleegers, Peetsma \& Oort conducted a study that supports the framework provided by the University of Oregon. The purpose of the study was to find out if teachers can motive students to learn. Through a variety of questionnaires to measure self-efficacy, academic mastery, goal orientation, intrinsic motivation, and performance avoidance, Thoonen et al. were able to support that a teacher's level of self- 
efficacy plays a pivotal role in the motivational behavior of both the teacher and the student.

Teachers that scored high on self-efficacy had students that reported higher motivational scores and showed more interest in academics. On the contrary, teachers that had lower self-efficacy scores had students that showed lower motivational scores and signs of apathy.

Research on motivation has been explored in two settings: athletic and academic. In both settings, all of the tools pertaining to motivation were described as beneficial and interchangeable. The basis for motivation is that students and athletes will be motivated if they are having fun (if it is relevant to them) and if they feel worthy (have a voice and belong). The ultimate goal in either setting is for the teacher or coach to create an environment that encourages an internal drive otherwise known as intrinsic motivation.

Intrinsic motivation can be defined as self-determination, inner desire, and viewing the simple satisfaction and pure enjoyment of performing the task as one's reward. Extrinsic motivation, on the other hand, comes in the form of other people. It can be both positive and negative and the rewards are usually tangible such as trophies, certificates, money, and publicity (Martens, 1987). 


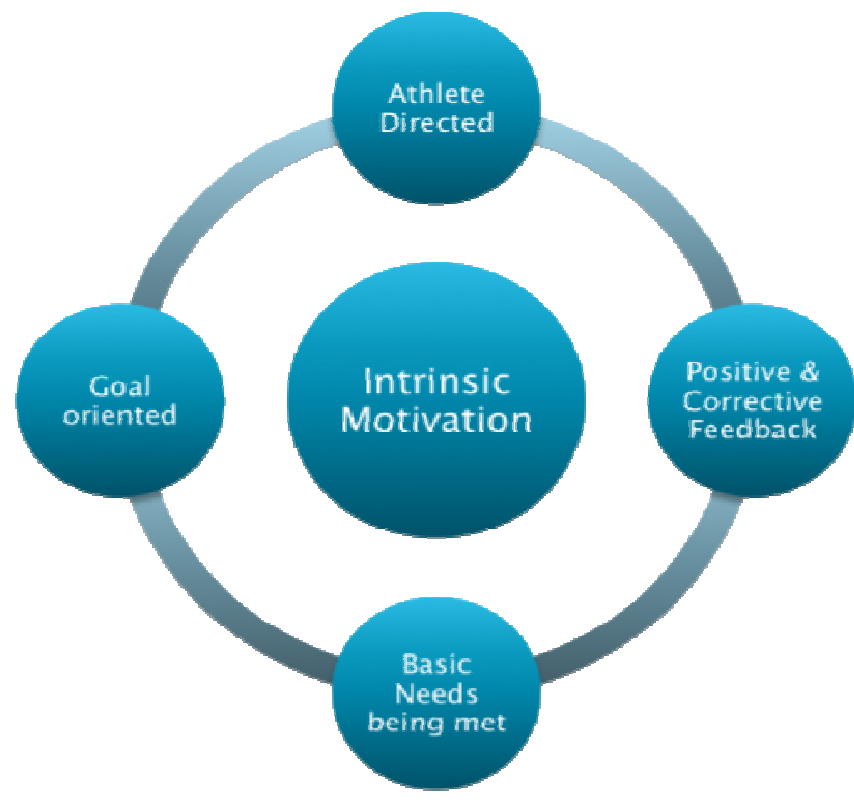

Figure 2.3: Components that Can Enhance Intrinsic Motivation

Despite the research that supports fostering intrinsic motivation, the traditional sources of motivation for athletics have revolved around extrinsic rewards and the importance of winning. In 2011, Responsible Sports found that athletes drop out of sports because the activity is no longer fun and the athletes are unable to handle the many pressures associated with winning. Coaches have an incredibly challenging task to create the appropriate atmosphere for continued participation in sports.

The reality of having all athletes achieve intrinsic motivation is unrealistic, so it is important to understand that not all forms of external/extrinsic rewards are negative. In some cases, the proper use of an extrinsic reward can lead individuals to further develop their intrinsic motivation. An example of this can be offering a new swimmer a certificate of achievement or stamps as they master new skills. The motivation to earn a 
certificate is externally driven but the notion that the athlete was able to accomplish a skill can be the basis for intrinsic motivation.

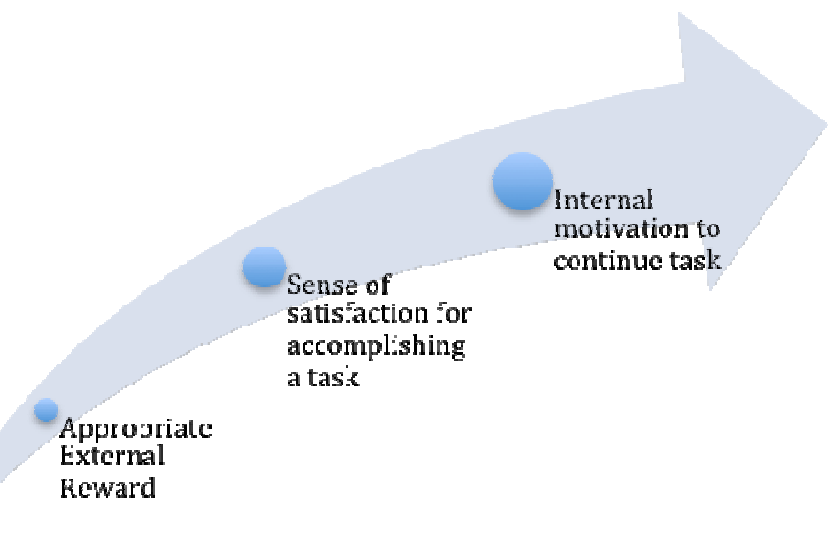

Figure 2.4: Extrinsic Reward and Intrinsic Motivation A basic external reward when used appropriately can lead to the satisfaction of accomplishing a skill and ultimately to intrisic motivation to continue a task.

When using extrinsic rewards, it is important to be careful, as external rewards can be detrimental to someone who is already intrinsically motivated. Athletes and students can also view extrinsic rewards as a way of being controlled by the coach or teacher. As a coach it is important to keep in mind that if rewards are given out that are not earned, they may be deemed worthless. An example of this can be a youth soccer team that gives everyone on the team a participation trophy at the end of the season. As the athletes age, the accumulation of these "participation" trophies may become meaningless since they do not signify any special accomplishments other than participation. The outcome could result in boredom with the course or sport and dropout may occur. 
The benefits of intrinsic motivation are that individuals participate because they enjoy what they are doing without having to be persuaded by any outside influences. Intrinsic motivation can increase self-esteem, competency, and offer a positive outlook on learning and ability (Martens, 1987).

In 2009, Lonsdale, Hodge, and Rose conducted a study about athlete burnout in elite sport. Elite Canadian athletes were used in the study to investigate relationships based on the self-determination motivation continuum and an athlete's response to burnout over time. Although burnout is different than dropout, it is important to be cognitive that motivational levels within athletes can lead to burnout and ultimately results in dropout.

The results of the study indicate "sport environments that promote needs satisfaction appear likely to promote more self-determined motivation and prevent athlete burnout" (Lonsdale et al., p. 794). The athletes that had a higher self-determination rating were able to curtail negative performance pressures and endure exhaustion associated with the demands of their sport.

With this knowledge it should be the goal of all coaches to create an environment in which athletes have the opportunity to learn by intrinsic motivation. The maturity level and age of athletes can play a role in a coach's ability to promote intrinsic motivation. Ultimately, the greatest successes are achieved through internalization. A key facet to the coaching profession is to offer a safe environment in which participants can grow and mature internally as much as possible. Maslow's Hierarchy of Needs is a great example for coaches to follow when building a motivational strategy. 


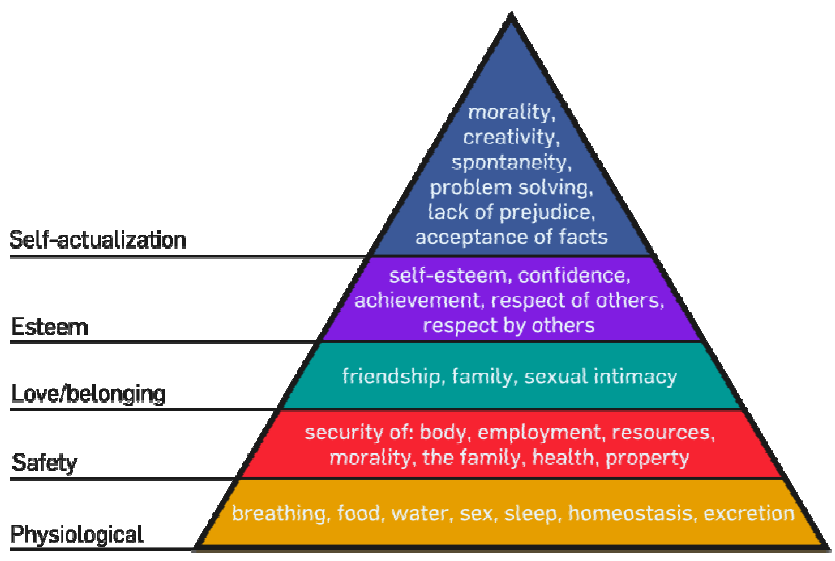

Figure 2.5: Maslow's Hierarchy of Needs

Maslow's Hierarchy of Needs can be a useful tool when developing programs for adolescent sports. From Maslow, 1943.

\section{Maslow's Hierarchy of Needs}

At the base of the hierarchy are basic physiological needs. These needs include satisfying hunger and thirst to simply survive. As a coach, it is important to realize that athletes need to stay properly hydrated and are eating appropriate nutritional meals that supplement the demands that their sport is putting on them. A coach must also be aware that these basic needs might not be met at home, which can affect how an athlete behaves at school or practice. At the next level of the hierarchy, people need to feel safe and secure. This is where teachers and coaches can create an environment that is safe and where growth and security are prevalent. Even if an athlete is coming from a detrimental situation outside of school, a coach can still offer a place that is safe and respectful. The third level of the hierarchy includes the need for love, belonging, and socialization. This is where the "fun" begins as far as coaching and teaching is concerned. Athletes in particular need to have fun in their sport and if they can relate their experiences to friends that are in the same situation, a positive social life will result. After social needs are met, 
the fourth level of the hierarchy involves esteem needs. If athletes have positive social experience through their sport and they are participating in a safe environment, their selfesteem is likely to be in good condition. Finally, in the fifth and final level of the hierarchy, an individual is capable of self-actualization (Martens, 1987).

An important aspect of Maslow's Hierarchy of Needs is that athletes must have their needs met on each level before they can move to the next level. This serves as a great reminder for the coach and the teacher to make sure they are truly meeting the needs of their participants. The simplistic idea of needs being met is the core in which motivation evolves. Having fun and feeling worthy are needs that every student and athlete possesses. When the elements on Maslow's Hierarchy of Needs are provided in a teaching or coaching environment, the result is self-actualization. In academics this means that a student is capable of becoming a life-long learner and in sports, an athlete's greatest reward becomes simply participating for the love of the game. Coaches and teachers play a vital role in young people's lives and by keeping in tune with the needs of their participants; motivation and success will likely follow.

In examining the various motivational climates it is important to explore how an athlete's individual and social perceptions influence participation in sport. According to Cox (2005), "social factors and psychological mediators are seen as determinants of motivation that lead to certain consequences" (p. 72). Many of the articles reviewed include the use of the Self-Determination Theory to define participation and motivation in sports. Additional theories that are commonly used in research on motivation in sports include the Achievement Goal Theory and Reversal Theory. To further understand an athlete's motivational behavior a closer look at all three theories is necessary. 


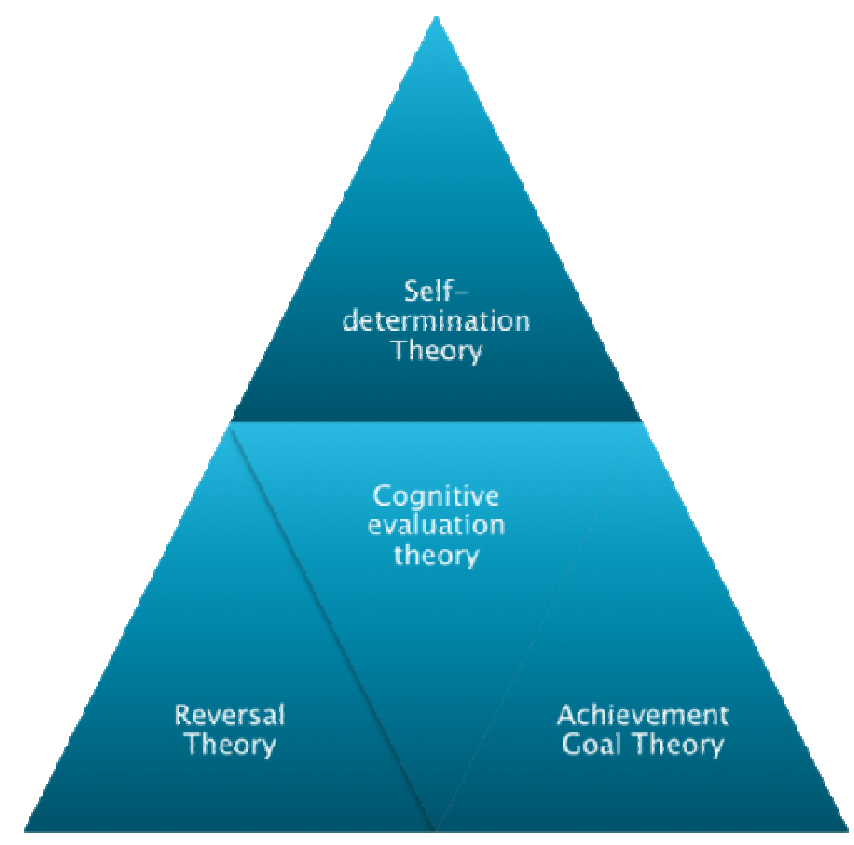

Figure 2.6: Theoretical Makeup of Motivation Theories used for the development of the Athlete Network.

\section{Self-Determination Theory}

To reiterate, it is important to understand the various levels of motivation.

Intrinsic motivation is a behavior that is performed for the pure pleasure and satisfaction of participation. Extrinsic motivation as described by the Self-Determination Theory has four subcategories: external regulation, introjected regulation, identified regulation, and integrated regulation. External regulation and introjected regulation are non-selfdetermined while identified regulation and integrated regulation are self-determined. Amotivation represents a lack of interest in continuing the behavior or participating in a sport (Boiche \& Sarrazin, 2006).

Scholars have found that higher levels of self-determined motivation (identified and integrated regulation) lead to overall higher intrinsic motivation scores and participation levels (Pelletier, Fortier, Vallerand, \& Briere, 2001; Sarrazin, Vallerand, 
Guillet, Pelletier, \& Cury, 2002). Essentially, the self-determined behaviors an athlete exhibits are excellent predictors of participation in a sport (Boiche \& Sarrazin, 2006). Furthermore, the motivational benefits of a coach that offers an environment that empowers athletes using autonomy-supportive coaching behaviors will positively predict motivational behaviors of an athlete to continue participation in sports (Amorose \& Anderson-Butcher, 2007). To further support the importance of self-determination motivation, Blanchard, Mask, Vallerand, de la Sablonniere, \& Provencher (2007) found that, "Environmental conditions that provide humans with the essential psychological nutrients necessary for vitality, growth, and optimal development, namely the need to feel autonomous, competent, and related to others are hypothesized to foster more autonomous or self-determined types of behavioral regulations" (p. 3).

In 2006, Reinboth \& Duda also found that a sporting environment that included specific task-involving features increased the likelihood of athlete wellbeing. One hundred twenty-eight British University athletes were used in the study and were asked to fill out questionnaires inquiring about perceptions of "motivational climate; the needs for autonomy, competence and relatedness" (p. 269). As mentioned earlier, autonomy involves the ability of individuals to implement their own ideas and choices into any given situation. The authors found that it is important that athletes be given a high level of autonomy to enhance overall motivational behaviors.

From a coaching perspective, coaches are responsible for the motivational climate that athletes must take part in and are therefore intimately responsible for how athletes perceive and respond to that climate. The more involved an athlete is within the taskinvolving features of a sporting program, the more likely they are to continue 
participation. Another positive result of having a program that encourages athlete autonomy is higher self-efficacy, which leads to higher levels of intrinsic motivation (Reinboth \& Duda, 2005).

In a similar study about autonomy, 581 male and female athletes were given questionnaires that assessed whether perceived competence, autonomy, and relatedness mediated the relationship between perceived autonomy-supportive coaching and athletes' motivational orientation (Amorose \& Anderson-Butcher, 2007). The results support the Self-Determination Theory and also support previous research on the motivational benefits of coaches that use autonomy-supportive coaching behaviors.

The specific methods coaches' use in developing their programs can directly affect the motivational outcomes of their athletes. How practice sessions are conducted, interactions between the coach and the athlete, and the athletes' perceptions of their autonomy influence overall motivational climates. If a coach does not encourage input from athletes, negative motivational effects may take place. The perceptions of a negative motivational climate can also encourage amotivation may (Boiche \& Sarrazin, 2007).

Additional research has added that both coach and peer motivational climates share responsibility for predicting outcome motivational behavior in athletes. The quality of the sporting experience does not rest solely on the shoulders of the coach. Peer involvement and acceptance in the motivational climate combined with the coach's influence can be either a positive or negative indicator of sport participation (Vazou, Ntoumanis \& Duda, 2006). 
In addition to peer and coach interactions, parents also play a key role in the motivational spectrum. Athletes that perceive negative parental pressure are more likely to have a decrease in self-efficacy that may lead to lower motivational behaviors. In 2006, Ullrich-French \& Smith found that the combination of "parent, peer group, and friendship relationships is critical to a full understanding of the social relationship linkage" (p. 193). A greater perception of acceptance by peer groups will result in less stress and overall enjoyment for the athlete.

\section{Achievement Goal Theory}

To investigate further into social and psychological aspects that affect the motivational climate, a look at the Achievement Goal Theory can be used. This theory is based on task orientation and ego orientation. Task orientation involves an athlete's desire to master the skills, engage in self-learning, and focus on overall improvements. Ego orientation is based on comparing one's skills to somebody else. Task orientation is closely related to intrinsic motivational behaviors while ego orientation is directly related to external motivational behaviors.

An example of an ego orientation that results in positive motivational behaviors is comparing results in an athletic competition with a teammate or competitor. If the athletes perceived that their athletic performance is greater than those to whom they are comparing themselves, then the athlete is likely to have a positive external motivational experience. This scenario is common among more highly skilled athletes. However, if athletes perceive their performance to be less than their competitors, a negative self- 
perception and self-worth may be the result, which can lead to amotivation (Sit \& Lindner, 2005; Vazou, Ntoumanis \& Duda, 2006).

The Achievement Goal Theory is an effective tool to help understand motivation and participation in sports. A common theme in the literature is to offer a program that encourages high levels of task orientation versus emphasis on ego orientation. Many athletes including elite level athletes use ego orientation (social acceptance) as part of their reward for their hard work but basing the program on task orientation (self/intrinsic motivation) will lead to higher overall motivational behaviors (Sit \& Lindner, 2005). It is important for a coach to realize the importance and prevalence of both task and ego orientation before an effective motivational climate can be developed.

\section{Reversal Theory}

In contrast to the Achievement Goal Theory's two variables (task and ego), the Reversal Theory is comprised of eight metamotivational orientations that determine sport participation. According to Lindner \& Kerr (2001), these categories represent "attitudes towards the behavior in the form of goal-directed (telic) vs. pleasure-directed (paratelic) orientations; control, competition or competence (mastery) vs. friendship, camaraderie (sympathy) orientations; self-centered (autic) vs. other-centered (alloic) orientations; and compliant (conformist) vs. rebellious (negativistic) orientations" (p. 761).

The primary difference between the Achievement Goal Theory and the Reversal Theory is that the Reversal Theory contends that motives to participate go beyond wanting to experience solely achievement. Individuals have many varying needs that must be met in order for participation in sports to continue. An athlete's mood states, 
perceptions of self-worth, peer perceptions, and environmental situations all play a part in determining the desire to participate in sports (Sit \& Lindner, 2005).

An athlete's motivational traits also play an important role in determining motivation in sports. In 2001, Reiss, Wiltz, \& Sherman found that "the more strongly people endorsed statements such as, 'Physical exercise is an essential part of my life', and 'I love physical exercise' the greater was the number of varsity sports in which they participated" (p. 1143). Reiss et al. developed the Reiss profile, which consists of 120 items that are scored into 15 motives to explore these phenomena.

Additional studies have shown that traits that involve sensation seeking in highrisk situations can attribute to the appropriate levels of arousal for continued participation. Extreme athletes such as kayakers, rock climbers, skiers and skydivers exhibit high levels of self-efficacy and intrinsic motivation even in instances where there are negative external perceptions present. In 1997, Slanger \& Rudestam found that "when people judge themselves capable of handling an activity, they perform with assurance, approach threatening tasks nonanxiously, experience little in the way of stress reactions, and are able to direct all effort to the task at hand rather than being disturbed by thoughts concerning their own capabilities" (p. 366-367).

Armed with this knowledge, the goal should be for coaches to create a motivational environment that offers athletes the opportunity to feel as though they are capable of handling any task. Although extreme athletes may exhibit stronger selfefficacy traits than an inexperienced team sport participant, empowering athletes at all levels is an important concept to consider in the coaching profession. 


\section{Summary}

There are many attributes that make up the motivational climate for participation in sport. The Self-Determination Theory, Achievement Goal Theory and Reversal Theory all offer excellent background information on what motivates people to participate in sports. It is important to understand the individual motives that include ego and task orientations as well as external perceptions from coaches, parents, and friends to fully understand motivation in sports.

The heart and soul of motivational theories are drive and incentive. The theories and research on motivation offer insight into the factors that lead to intrinsic motivation, extrinsic motivation and amotivation. Personality, behavior, mastery, perceptions of selfworth, peer perceptions, and environmental factors all play an important role in the makeup of motivation. The basis of this project was to embed the theories of motivation into a medium that will help foster intrinsic motivation among participants. 


\section{CHAPTER 3: METHODS AND PROCEDURES}

The purpose of this project was to provide an interactive online "toolbox" or resource center to benefit and educate athletes. The overall objective was to use primary constructs of motivation and disseminate the information in a medium that engages a modern and technologically savvy generation. This chapter contains information on a) the steps I followed to develop the website, b) ethical considerations and principals used in the development of the website and c) descriptions of the main motivational tools within the website.

\section{Development of the Website}

I purchased the domain name "www.athletenet.net" and linked it to my swim club's website (www.pumaswim.org). The content of the site was made available to a select group of Puma Aquatic team members for responses included in the defense of this project. I developed the website with the help of a software engineer who is a friend and colleague. This online motivational guide, called the "Athlete Network", is for the sole use of athletes, parents, and coaches who are members of the Puma Aquatic Team.

Athletes have the capability to login to the site and keep a daily practice journal in which they can rate their effort and performance as well as include notes on technique and overall physical health and well-being. A vital aspect of the website provides athletes with the opportunity to establish daily, weekly, season, short-term, long-term, practice, and dream goals. More importantly, athletes can chart their progress, update 
goals, and communicate with their coaches. Athletes can also participate in a team blog in which they can communicate with other teammates to help build team spirit.

The online program also helps educate parents on their role in creating a favorable motivational climate for their child. Parents have the capability to login to the website and have access to valuable resources to support intrinsic motivation. As the site further develops, parents will also be able to participate in online "parent meetings" and "coaching webinars".

Topics such as self-efficacy, imagery, burnout, mastery, and feedback are available for all visitors to the website with additional sections devoted to coaches and parents. The goal was to bring the theories of motivation and put them to practice by using "cloud networking" on the Internet as an effective communication platform for athletes.

\section{Ethical Considerations and Responsible Use}

Members of the Athlete Network may choose specific privacy settings based on their personal preferences and are required to read and agree to a privacy disclosure before access to the website is granted. This gives each user a choice of what information will be shared with other users of the site. There are some legal ramifications that are being worked out before wide use of the Athlete Network is initiated.

\section{Website Components}

The Athlete Network is comprised of seven main components, which will be individually discussed on the following pages: 
1. Login screen

2. Home page for swimmers

3. Goal-setting page for swimmers

4. Journal page for swimmers

5. Practice performance rating page for swimmers

6. Athlete performance chart for swimmers

7. Competition results page for athletes

\section{Login Screen}

Each time the site is accessed, swimmers will input their username and password to login to the site. Only current members of the Puma Aquatic Team are currently able to create an account. The site is encrypted for security purposes and has the capability to send members username and password information if they have forgotten either one.

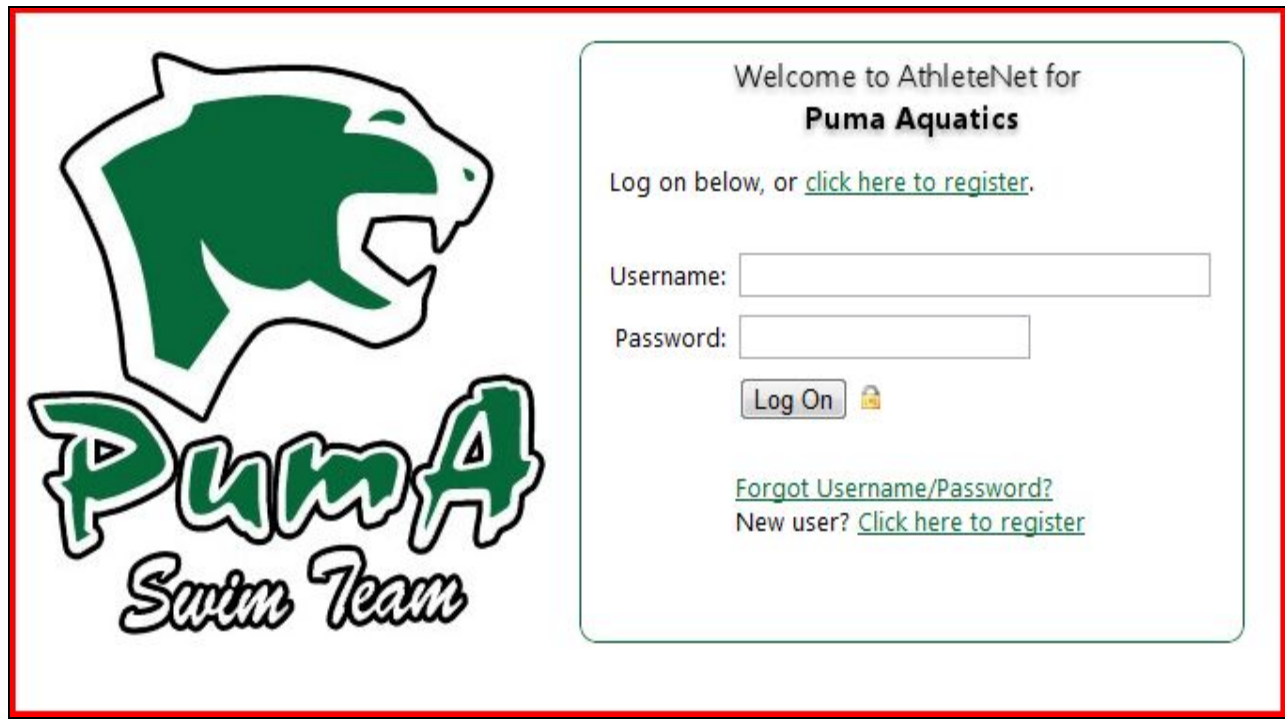

Figure 3.1: Athletenet.net Login Page for Puma Aquatic Team Swimmers 


\section{Home Page for Swimmers}

The home page enables swimmers to post instant blog messages that are archived and accessible to all members that have access to the Athlete Network. In an effort to uphold appropriate use of the site, the Athlete Network does not have "member to member" instant blogs or chat rooms. The home page also acts as a gateway to access goal setting, daily journal, practice rating, practice performance, race performance, and team performance tools. Members can also visit the team store to order team apparel, update personal account information and visit the resource center that provides background information and research on motivation.

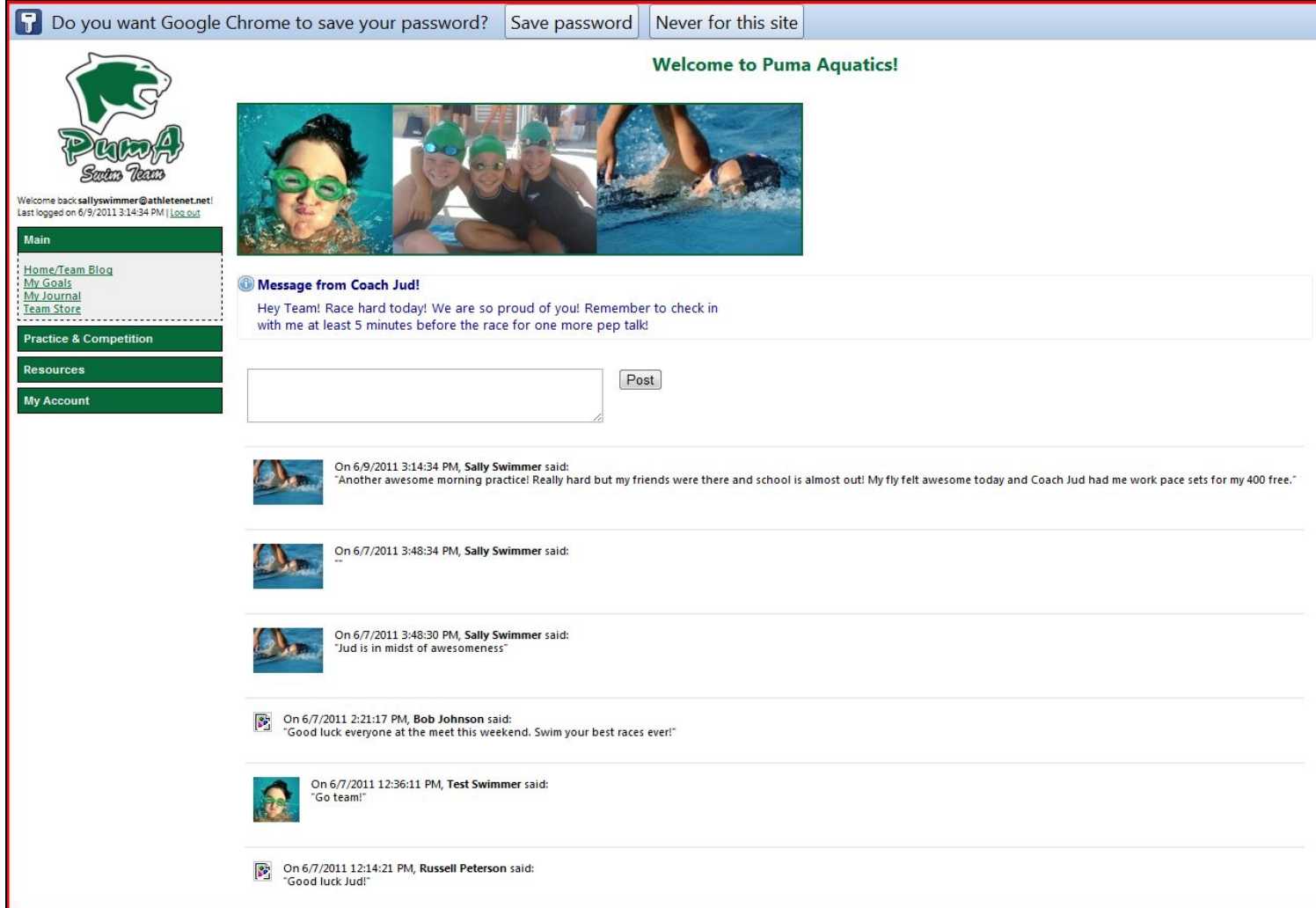

Figure 3.2: Athletenet.net Home Page for Swimmers 


\section{Goal-Setting Page for Swimmers}

Swimmers can create practice/technique goals, short-term goals, long-term goals, and dream goals. Swimmers can update their goals and edit them at any time and share goals with their coaches if they wish. Once a goal is achieved a swimmer can acknowledge his or her achievement, mark off that the goal has been attained, and it will be archived automatically for future reference. If a swimmer is unsure of what the definition of a goal is, he or she can scroll over the specific goal and a bubble appears with the definition of the goal as well as suggestions on how to develop it. AJAX HTML Editor Control was used for the toolbox to offer a variety of writing functions.

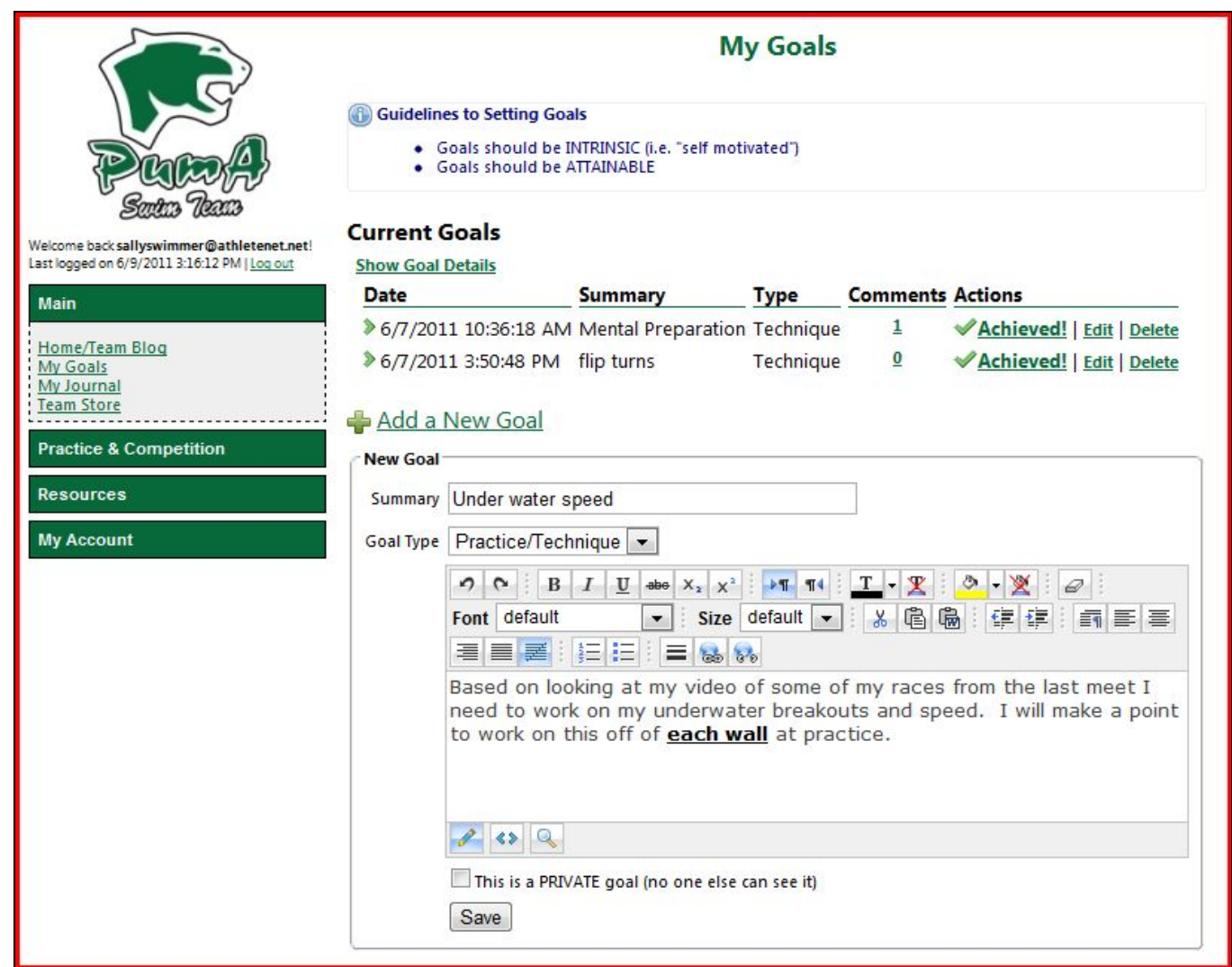

Figure 3.3: Athletenet.net Goal Setting Page for Swimmers 


\section{Journal Page for Swimmers}

Swimmers have the capability to create a daily online journal and can keep it private or share with their coach. Journal entries are archived and can be accessed, edited or deleted at any time. There are no limits to how many daily entries a swimmer can make. This is an important tool for swimmers to use as it provides a written history of the psychological and physiological states of a swimmer to refer back to as a valuable tool at anytime. The design of the journal was kept simple so that athletes can easily and quickly write an entry without feeling over whelmed by the task at hand. When creating a new journal entry, swimmers can also see previous journal entries as a reference. Swimmers can also print designated journal entries and will be able to print daily, weekly, and monthly journals in a future version of the software.

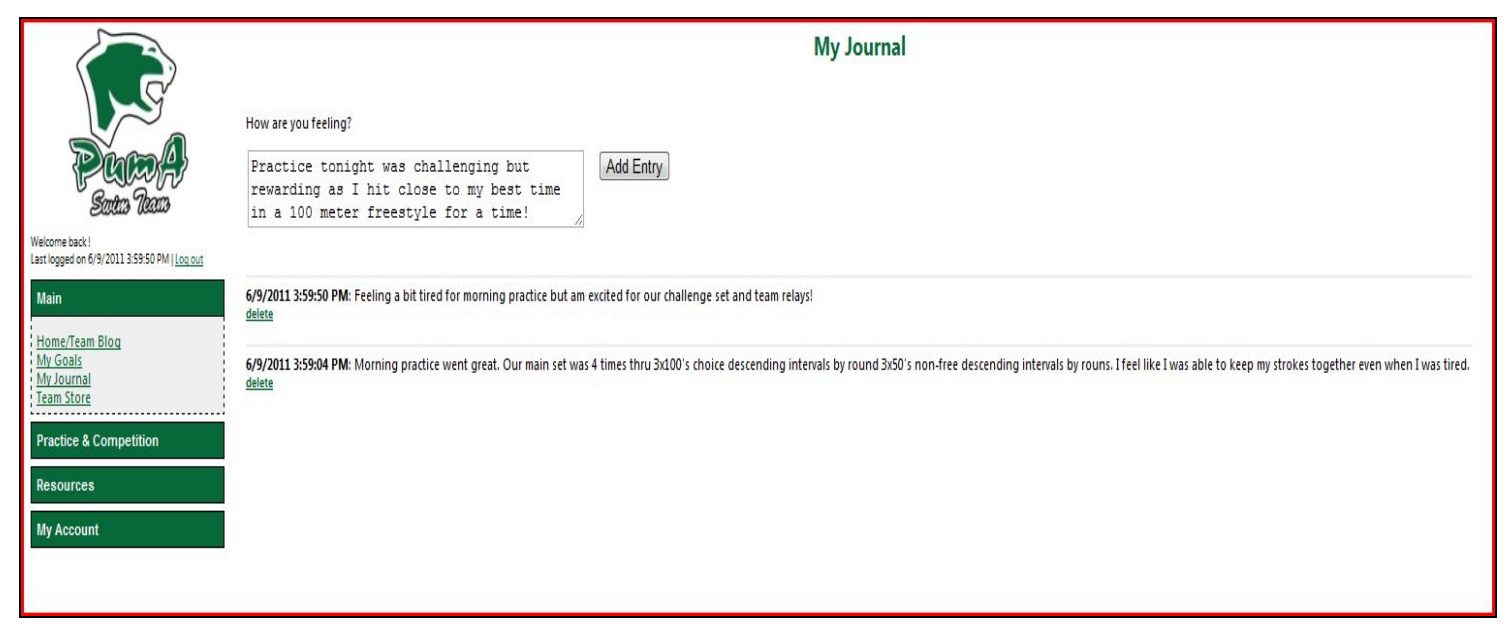

Figure 3.4: Athletenet.net Journal Page for Swimmers 


\section{Practice Performance Rating Page for Swimmers}

Swimmers can rate their daily practice performance and how they felt on a scale from 1-5 with 1 being "terrible" and 5 being "great". A simple "bubble" to check for each rating on the scale makes it easy for swimmers to quickly click their selection. After a swimmer clicks their selection they can write in a text box how they felt and provide descriptive detail on why they rated their performance the way they did. Swimmers can see previous practice performance ratings and notes as well as create a chart or graph based on a user-defined period of time. Please refer to Figure 3.6 for a sample version of a graph.

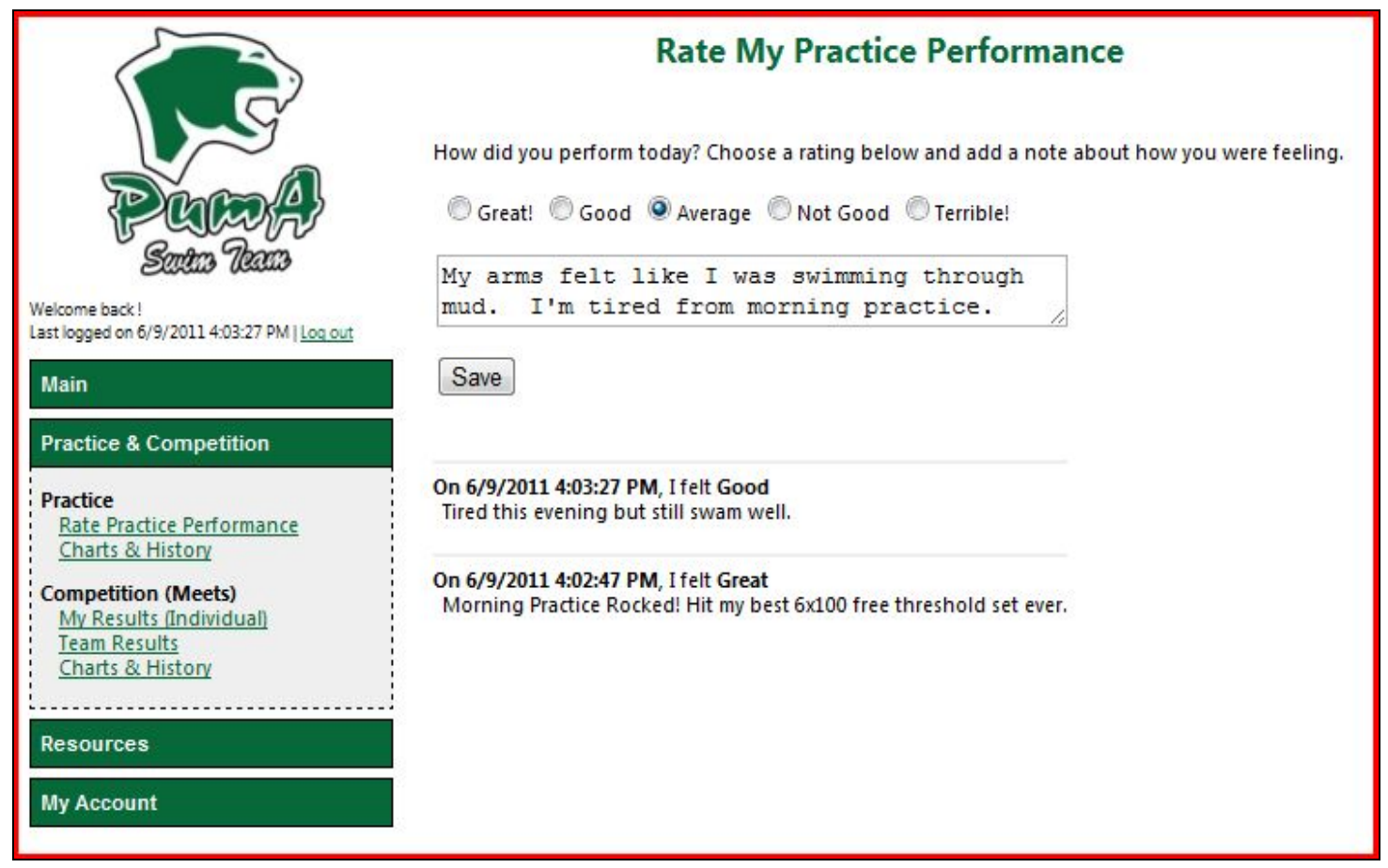

Figure 3.5: Athletenet.net Practice Performance Rating Page for Swimmers 


\section{Performance Charts and Graphs for Swimmers}

Swimmers can access statistical charts and graphs based on average daily performance ratings over a given period of time. In Figure 3.6 the graph represents daily performance ratings over a 1-year period. This can be valuable information for a swimmer as it can be compared to performance outcomes at competitions for the same period of time. If a swimmer feels that they are not performing well in meets, a practice performance graph can show possible correlations between practice performance and competition performance. Swimmers will be able to create weekly, monthly, bimonthly, quarterly, and yearly graphs and charts in a future version of the software.

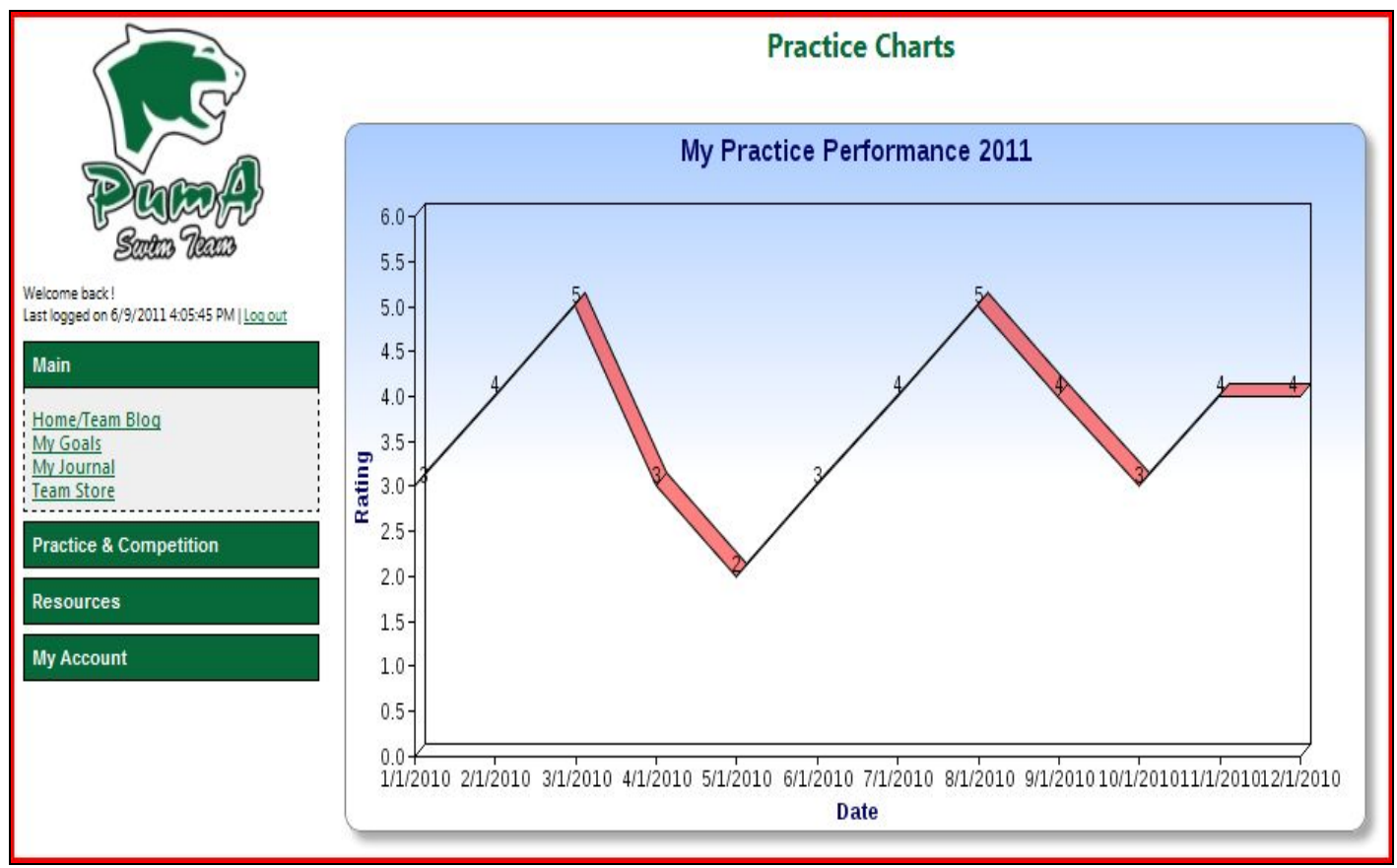

Figure 3.6: Athletenet.net Athlete Performance Chart for Swimmers 


\section{Competition Results for Athletes}

Swimmers will have the capability to access all individual meet results that can aid in the implementation of performance goals as well as practice goals. In this example a swimmer can see her official splits from an 800-meter freestyle race that she swam in a past meet. Swimmers that are familiar with their splits can use them to develop goals for target times to achieve in practice. A graph will depict time improvements and or gains over a specified search period as defined by the swimmer. Competition results coupled with practice performance ratings offer valuable information to swimmers to receive a broad perspective of how practice performance may relate to competition performance.

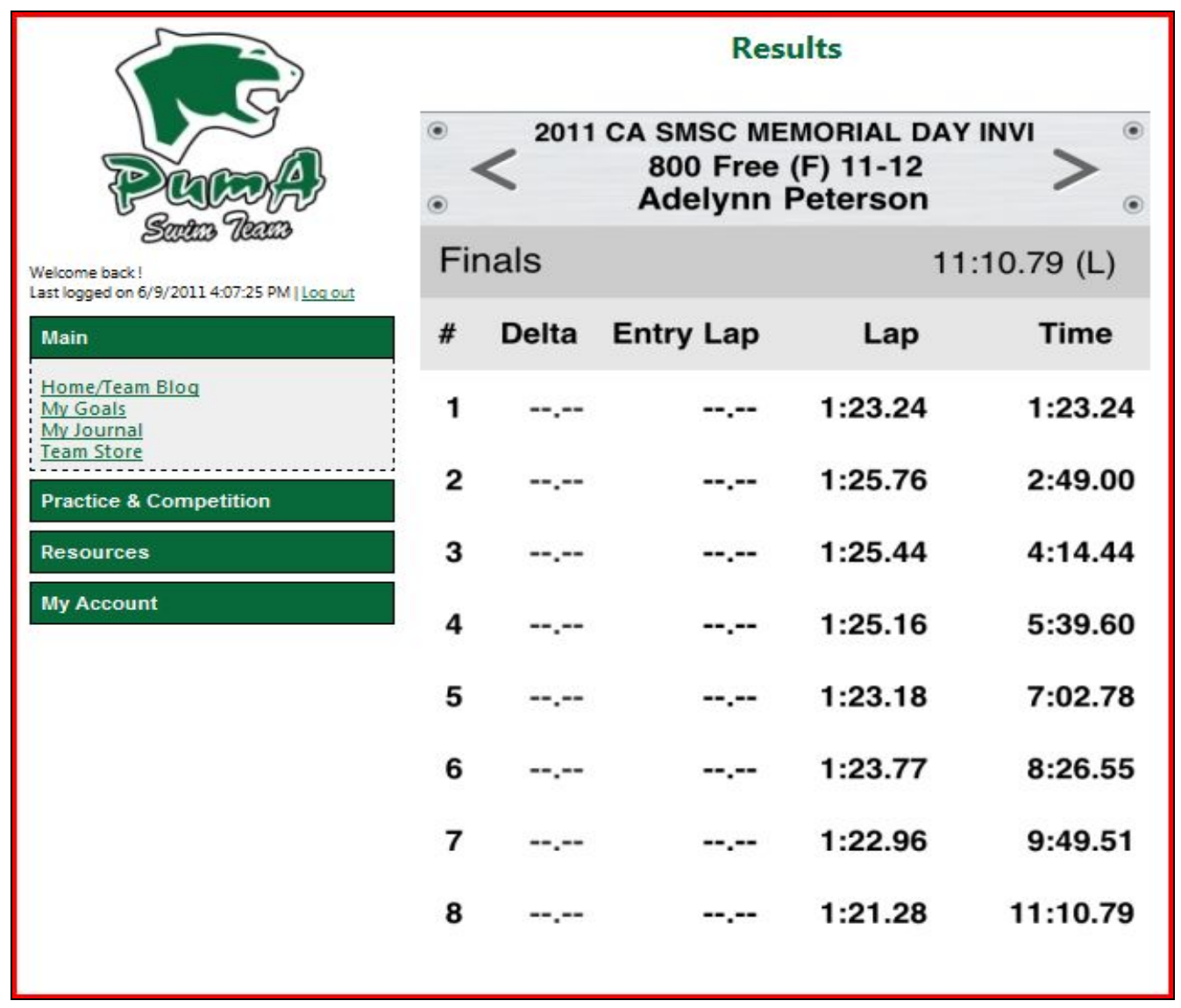

Figure 3.7: Athletenet.net Competition Results for Athletes 


\section{CHAPTER 4: RESULTS AND CONCLUSION}

\section{Overview of Project}

The purpose of this project was to provide an interactive online "toolbox" or resource center to benefit and educate athletes. The overall objective was to use primary constructs of motivation and disseminate the information in a medium that engages a modern and technologically savvy generation. An integral part of the online toolbox is its avenues for greater communication between coaches, athletes, and parents, which helps create and maintain an environment that cultivates intrinsic motivation.

Ultimately, athletes can establish a variety of practice and competition goals, keep an online journal, rate performance and effort, and communicate with teammates and coaches on a team blog en-route to continued participation and self-efficacy. This chapter contains, a) an athlete evaluation of the website, b) swimmer feedback, c) future possibilities and capabilities, d) conclusion and e) recommendations and suggestions for future studies.

\section{Athlete Evaluation}

The Athlete Network beta version was demonstrated and evaluated by ten (10) Puma Aquatic Team members. All swimmers were in the Platinum-Senior level swim groups that are proven proficient swimmers with extensive competitive experience. Although the site was not "live", athletes provided ratings on the following topics: "Athlete Journal”, “Athlete Practice Rating”, “Athlete Goal Setting”, and "Swimmer/Team Blog". The ratings, which are shown in Table 4.1, were based on a 
Likert-type scale:

1: Will not use

2: May use but not likely

3: Will use but not sure how much

4: Good and will use frequently

5: Awesome! Will use regularly

Table 4.1: Swimmer Response to Website Tools

\begin{tabular}{lccccc}
\cline { 2 - 6 } & \multicolumn{5}{c}{ Rating Scale (percent of user response) } \\
\hline Website Tools & $\mathbf{1}$ & $\mathbf{2}$ & $\mathbf{3}$ & $\mathbf{4}$ & $\mathbf{5}$ \\
\hline Athlete Journals & - & - & - & - & 100 \\
Athlete Practice Rating & - & - & - & 10 & 90 \\
Athlete Goals & - & - & - & 20 & 80 \\
Team Blog & - & - & - & - & 100 \\
\hline
\end{tabular}

\section{Swimmer Feedback}

Table 4.1 provides an overview of the initial feedback I received from 10 swimmers. This initial exposure to the website provided swimmers with an opportunity to give me feedback on their perceptions of the usability of this online resource.

- Athlete Journal: $100 \%$ gave a 5 rating. The swimmers reported this tool easy to use to post practice notes, and they especially liked the options they could use for creating their journal entries.

- Athlete Practice Rating: 90\% gave a 5 rating \& 10\% gave a 4 rating. Swimmers liked the practice rating scale; however, they wanted to see what a graph would look like over a given period of time. The graph is still being developed. 
- Athlete Goal Setting: $80 \%$ gave a 5 rating \& $20 \%$ gave a 4 rating. The majority of swimmers felt that they were going to use this aspect of the website consistently. A few of the younger swimmers wanted more descriptions about each type of goal so that they had more knowledge on how to effectively create their goals. Descriptions of each goal and goal setting guidelines have since been developed.

- Swimmer/Team Blog: 100\% gave a 5 rating. The swimmers were really excited about this feature and the capabilities of being able to communicate directly with other teammates. A few swimmers were interested in being able to post photos and were excited about when that feature will be available.

Although the athlete response is small in number the results indicate that the tools that comprise the Athlete Network are relevant and will be used frequently. Many of the swimmers mentioned that a smart phone application would most likely be used more frequently than the website. A smartphone application for the Athlete Network is something that will be developed as the Athlete Network continues to grow. The vision for the Athlete Network is that the website capabilities will act as the hub of content while the smart phone application(s) will be the driving force for ease of use.

\section{The Athlete Network: Future Possibilities and Capabilities}

The general framework that has been set up for The Athlete Network is something that can be modified to be used effectively in the educational setting, for personal 
exercise maintenance and goal setting, commercial health club setting, diet and nutrition, professional, amateur, and youth sports, music classes, etc.

As the Athlete Network continues to grow, the possibility of implementing the site as a recruiting tool for universities will be explored. Another addition will be the implementation of an "age appropriate" goal setting page aimed for swimmers that are 610 years old.

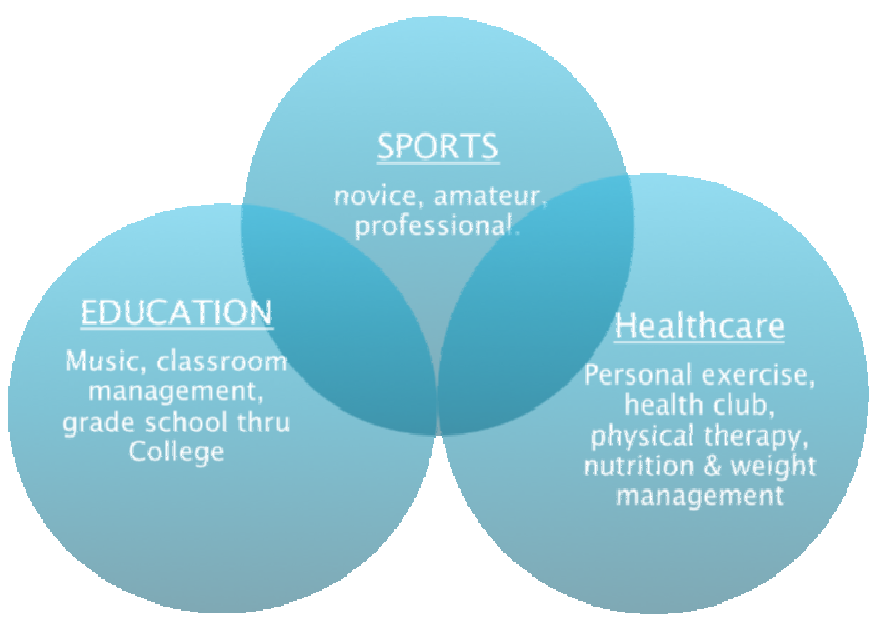

Figure 4.1: Potential Areas of Use for the Software

\section{Conclusion}

In 1999, Iso-Ahola defined motivation as "the forces that initiate, direct, and sustain behavior" (p. 35). The "forces" or the drive behind motivation are known as “intrinsic motivation" and "extrinsic motivation.” Martens (1987) explained that extrinsic rewards in the right setting can help spark intrinsic motivation; however, if used incorrectly rewards can lead to disinterest and possible dropouts. Coaches should strive to create an environment in which intrinsic motivation among athletes can flourish. If an 
athlete feels safe, respected, and has a voice then ultimately his or her participation will continue for the pure love of the sport.

Despite ample resources available to athletes, coaches, and parents, adolescents are dropping out of sports at alarming rates. In an effort to lower attrition rates among adolescent athletes, the Athlete Network has been created to help promote a healthy environment among and between athletes that encourages intrinsic motivation. With the use of online journals, goal setting, practice and competition progress charts, and an array of functional motivational tools, athletes now have a means to define their own success.

\section{Recommendations and Suggestions for Future Studies}

Future studies could involve empirical studies in which researchers examine the extent to which these interactive tools enhance intrinsic motivation and decrease swimmer dropout rates. For example, a study involving three (3) groups of swimmers with 20 swimmers in each group could be researched over a 16-week training and competition period. Group A would complete the season with no input from the coaching staff about keeping a written journal or establishing goals. Members of Group A would simply be training and competing with regular daily interactions with their coaches on the pool deck and would not have access to the Athlete Network. Group B would have full access to the Athlete Network and participate in daily logs, practice ratings, and goal setting, and would receive feedback on a daily basis from the coaching staff. Group C would have access to traditional motivational tools in the form of a written journal and goal setting guidelines and would be able to communicate them with the coaching staff. 
At the end of the 16-week cycle, athletes in each group would complete an athlete questionnaire to rate their levels of motivation. The study is capable of producing some answers to a variety of intriguing questions such as: How effective is the Athlete Network at enhancing intrinsic motivation? Which training group is more likely to experience burnout? How does the group that had access to the Athlete Network compare when looking at intrinsic motivation scores to the group that had traditional forms of written journals and goals? Performance in meets and practice can also be objectively obtained by comparing all three groups based on individual results at the start of the 16-week season and results at the end of the season. 


\section{REFERENCES}

Ames, C. (1992). Achievement goals, motivational climate and motivational processes. In G. Roberts (Ed.), Motivation in sport and exercise 161-176. Champaign, Il: Human Kinetics.

Amorose, A.J., \& Anderson-Butcher, D. (2007). Autonomy-supportive coaching and self-determined motivation in high school and college athletes: A test of selfdetermination theory. Psychology of Sport and Exercise, 8 (5) 654-670.

Anshel, M.A. (2003). Sport psychology: from theory to practice. (4th Edition). Benjamin Cummings: San Francisco, CA.

Bandura, A. (1997). Self-efficacy: The exercise of control. Freeman: New York

Baric, R., \& Bucik, V. (2009). Motivational differences in athletes trained by coaches of different motivational and leadership profiles. Faculty of Kinesiology, University of Zagreb, Croatia \& Department of Psychology, Faculty of Arts, University of Ljubljana, Slovenia. 181-194.

Beaudoin, C.M., (2006). Competitive orientations and sport motivation of professional women football players: An internet survey. Journal of Sport Behavior. 29 (3) 201-211.

Blanchard, C.M., Mask, L., Vallerand, R.J., de la Sablonniere, R., \& Provencher, P. (2007). Reciprocal relationships between contextual and situational motivation in a sport setting. Psychology of Sport and Exercise, 8 (5) 854-873. 
Boiche, J.C.S., \& Sarrazin, P.G. (2007). Self-determination of contextual motivation, inter-context dynamics and adolescents' patterns of sport participation over time. Psychology of Sport and Exercise, 8 (5) 685-703.

Center for Disease Control. (2011). Childhood Obesity. Retrieved March 12, 2011 from http://cdc.gov/obesity/childhood/index.html

Cox, R. (2005). Sport Psychology: Concepts and Applications ( $5^{\text {th }}$ edition). Boston: McGraw-Hill Higher Education.

Deci, E.L. \& Ryan, R.M., (1985). Intrinsic motivation and self-determination in human behavior. New York: Plenum Press.

Deci, E.L. \& Ryan, R.M., (1991). A motivational approach to self: Integration in personality. In R. Dienstbier (Ed.), Nebraska symposium on motivation: Perspectives on motivation, Lincoln, NE: University of Nebraska Press. 38, 237288.

Duda, J.L. (1989). Relationship between task and ego orientation and the perceived purpose of sport among high school athletes. Journal of Sport and Exercise Psychology, 11, 318-335.

Duda, J.L., Chi, L., Newton, M.L., Walling, M.D., \& Catley, D. (1995). Task and ego orientation and intrinsic motivation in sport. International Journal of Sport Psychology, 26, 40-63.

Goldstein, A. (1994). Addiction: From biology to drug policy. Freeman: New York Iso-Ahola, S. (1999). Motivational foundations of leisure. In E.L. Jackson \& T.L. Burton (Eds). Leisure Studies: Prospects for the twenty-first century. (p. 35-51). State College, PA: Venture Publishing. 
Kraft, U. (2006). Burned Out. Scientific American Mind. June/July (p. 28-33)

Lindner, K.J., \& Kerr, J. (2001). Predictability of sport participation motivation from metamotivational dominances and orientations. Personality and Individual Differences, 30, 759-773.

Lonsdale, C., Hodge, K., \& Rose, E. (2009). Athlete burnout in elite sport: A selfdetermination perspective. Journal of Sports Sciences, 27(8), 785-795.

Martens, R. (1987). Coaches guide to sport psychology. Human Kinetics: Illinois.

Maslow, A. H. (1943). A theory of human motivation. Psychological Review, 50, 370-96.

Pelletier, L., Fortier, M., Vallerand, R., \& Briere, N. (2001). Associations among perceived autonomy support, forms of self-regulation, and persistence: A prospective study. Motivation and Emotion, 25, 279-306.

Reinboth, M., \& Duda, J.L. (2006). Perceived motivational climate, need satisfaction and indices of well-being in team sports: A longitudinal perspective. Psychology of Sport and Exercise, 7, 269-286.

Reiss, S., Wiltz, J., \& Sherman, M. (2001). Trait motivational correlates of athleticism. Personality and Individual Differences, 30, 1139-1145.

Responsible Sports (2011) Staying in love with sports. Retrieved March 10, 2011 from http://responsiblesports.com/youth_sports_advise/monthly_enewsletter.html Sarrazin, P., Vallerand, R., Guillet, E., Pelletier, L., \& Cury, F. (2002). Motivation and dropout in female handballers: A 21-month prospective study. European Journal of Social Psychology, 32, 395-418. 
Sit, C.H.P., \& Lindner, K.J. (2005). Motivational orientations in youth sport participation: Using achievement goal theory and reversal Theory. Personality and Individual Differences, 38, 605-618.

Slanger, E., \& Rudestam, K.E. (1997). Motivation and disinhibition in high risk sports: Sensation seeking and self-efficacy. Journal of Research in Personality. 31, 355374.

Thoonen, E., Sleegers, P., Peetsma, T., \& Oort, F.J. (2011). Can teachers motivate students to learn? Educational Studies. 37, 3, 345-360.

Ullrich-French, S., \& Smith, A.L. (2006). Perceptions of relationships with parents and peers in youth sport: Independent and combined prediction of motivational outcomes. Psychology of Sport and Exercise, 7, 193-214.

University of Indiana (2011). Why kids ditch youth sports. Retrieved May 15, 2011 from http://newsinfo.iu.edu/web/page/normal/3885.html

University of Oregon (2002). Motivating students. Retrieved May 3, 2005, from http://tep.uoregon.edu/resources/faqs/motivatingstudents/motivating.html

USA Swimming (2011). 2010 Membership demographics. Retrieved March 12, 2011 from http://usaswimming.org/_rainbow/documents/db2b00db-8156-44c3-8364e2b4d3e0b0d/statistics-2010.pdf

Vazou, S., Ntoumanis, N., \& Duda, J.L. (2006). Predicting young athletes' motivational indices as a function of their perceptions of the coach- and peer-created climate. Psychology of Sport and Exercise, 7, 215-233. 